\title{
A JUSTIÇA RESTAURATIVA: UM NOVO PARADIGMA COMO INSTRUMENTO DE RESSOCIALIZAÇÃO DO JOVEM ADULTO ${ }^{1}$
}

\author{
Renata Aparecida Follone* \\ Cassiane de Melo Fernandes** \\ Gustavo Renê Mantovani Godoy***
}

\begin{abstract}
Resumo
O presente trabalho objetiva trazer a Justiça Restaurativa como paradigma instrumental de ressocialização dos jovens adultos infratores, traçando o seu viés como medida de solução de conflitos penais mais eficaz e pacífico, de modo que todos os indivíduos atingidos na lide, saiam satisfeitos com os resultados de menor invasão à direitos fundamentais. Considera-se o comparativo do atual sistema retributivo/ressocializador adotado no Brasil, diga-se ineficiente, que tem como finalidade a punição do ofensor como plano central. Em contrapartida, a Justiça Restaurativa, um procedimento de consenso, de composição entre os atores processuais primários e secundários afetados direta e indiretamente pela prática criminosa.
\end{abstract}

Palavras-chave: Justiça Restaurativa; Justiça Retributiva; Jovem adulto; Novo paradigma; Resolução de conflitos criminais.

\section{RESTORATIVE JUSTICE: A NEW PARADIGM AS AN INSTRUMENT FOR THE RESOCIALIZATION OF ADULT YOUNG PEOPLE}

\begin{abstract}
* Doutoranda e Mestre em Direitos Coletivos, Cidadania e Função Social do Direito do PPGD da Universidade de Ribeirão Preto/UNAERP; Bolsista PROSUP/CAPES; Especialista em Direito do Trabalho e Processo do Trabalho pela - Universidade Gama Filho/UGF; Membro da Associação Mundial de Justiça Constitucional; Presidente da Comissão "OAB vai à escola" da 241ª OAB-sp; Docente; Advogada; Orcid iD: https://orcid.org/0000-0002-3470-3615; e-mail:rfollone@uol.com.br

** Mestre em Direitos Coletivos e Cidadania pela UNAERP; Membro da Associação Mundial de Justiça Constitucional; Professora da Faculdade de Barretos-FB Conciliadora e Mediadora do TJ-SP; Advogada; Orcid iD: https://orcid.org/0000-0003-0319-2442; e-mail: cassiane.cueb@terra.com.br

*** Mestre em Direitos Coletivos e Cidadania pela UNAERP-Universidade de Ribeirão Preto; Professor da Faculdade de Barretos-FB, Advogado em enfoque de atuação na área penal e processual pena; Orcid iD: https://orcid.org/0000-0002-8897-3960; e-mail: ggodoy341@ gmail.com

1 "O presente trabalho foi realizado com apoio da Coordenação de Aperfeiçoamento de Pessoal de Nível Superior - Brasil (CAPES) - Código de Financiamento 001”.
\end{abstract}


The presente work aims to bring Restorative Justice as an instrumental paradigm for the resocialization of young adult offenders, outlining its bias as a more effective and peaceful solution to criminal conflicts, so that all individuals affected in the dispute, leave satisfied with the results of lesser invasion of fundamental rights. It is considered the comparative of the current retributive/resocializing system adopted in Brazil, say inefficient, which aims to punish the offender as a central plan. In contrast, Restorative Justice, a consensus procedure, composed of primary and secondary procedural actors directly and indirectly affected by criminal practice.

Key words: Restorative Justice; Retributive Justice; Young adult; New paradigm; Esolution of criminal conflicts.

\section{INTRODUÇÃO}

O atual modelo de justiça utilizado no Brasil, primordialmente, é o retributivo, ou seja, é aquele no qual o Estado por meio do ius puniend tem o dever-poder de punir aquele indivíduo, que descumpre o ordenamento jurídico, fazendo assim, com que seja aplicada uma pena ao transgressor e este pague pelo ato em desconformidade legal praticado. Ocorre que esse sistema penal não preza e não contribui pela ressocialização do réu, também um dos pilares relacionados a punição, tampouco restaura a situação jurídica em que a vítima se encontrava antes de sofrer com a prática do crime. $\mathrm{O}$ encarceramento deveria atender as necessidades sociais de proteção e punitivas, de modo que promovesse a reeducação dos agressores, a fim de ressocializá-los, porém, na prática, não é assim que ocorre, especificamente, no caso dos jovens infratores. As cadeias viraram sedes de terror, onde a dignidade humana não é observada, o destrato e mau-caso integra o indivíduo e não se obtém um resultado positivo diante da situação.

No caso dos jovens infratores, o modelo retributivo também não é eficaz no que concerne a coibir o jovem a não praticar delito ou de fazê-lo a não reincidir na prática de atos ilícitos e, consequentemente, na ressocialização.

Por conta disso, tem-se buscado um meio alternativo para resolução mesmo no aspecto criminal de modo que a maneira de se buscar uma melhor solução seja mais eficaz, e é a partir daí, que a Justiça Restaurativa vem tomando proporções e ganhando destaque. No âmbito internacional foi decretado pela ONU, a Resolução 12/2002, como apoio ao método restaurativo e, no Brasil, a Resolução 225/2016, do CNJ implementou a Justiça Restaurativa 
com respaldo jurídico para a uniformização na conceituação de tais práticas. E a Resolução no 300, de 29 de novembro de 2019, onde dispõe sobre a Política Nacional de Justiça Restaurativa no âmbito do Poder Judiciário e de outras providências, mostra a preocupação das autoridades em apresentar uma solução de conflitos mais pacífica e rápida, de modo que verse sobre a restauração da vítima, tanto quanto a do agressor, no âmbito penal e social também.

A Justiça Restaurativa (Restorative Justice), ou Reintegrativa, termo utilizado pela primeira vez em artigo desenvolvido por Albert Eglash, em 1977, denominado “Beyond Restitucion: Creative Restitucion". Inserido na obra escrita por Joe Hudson e Burst Gallaway, "Restitucion in a Criminal Justice", nasce num contexto internacional de crise de legitimidade do modelo de justiça penal até então utilizado, o modelo retributivo.

A mesma, propõe a resolução de conflitos no âmbito penal, mediante a aplicação de uma metodologia voltada ao diálogo entre as partes envolvidas e a comunidade local onde ocorreu a infração a fim de que seja alcançada a reparação do dano sofrido por parte da vítima e quando for possível, restabelecer as relações rompidas, ela apresenta-se como um modelo adverso ao retributivo, pois é caracterizada não pela punição como aquela, mas sim pela restauração das relações dos indivíduos e reparação do dano sofrido de forma mais rápida, caso fosse decidida em justiça mediante um terceiro alheio ao fato.

Por fim, diante da atualidade e relevância do tema, traz-se a reflexão sobre a possibilidade de aplicação das práticas da Justiça Restaurativa em situações ilícitas praticadas por jovens, os quais devem ser tratados de forma humanizada, tentando estimular neles o sentimento de responsabilidade, tanto para a vida pessoal e familiar como para a vida em sociedade, bem como educando-os a não mais praticar delitos.

Como conclusão, apresenta-se as considerações e viabilidade oriundas das pesquisas realizadas, com a singela e modesta intenção de contribuir e, jamais de se esgotar a discussão, para que a aplicação da Justiça Restaurativa possibilite uma medida de enfrentamento à ressocialização eficaz dos jovens infratores e, ainda, traga a efetivação das transformações das dimensões humanas e sociais e a garantia da dignidade da pessoa humana.

\section{A JUSTIÇA RESTAURATIVA: UM NOVO PARADIGMA DE RESOLUÇÃO DE CONFLITOS CRIMINAIS}

Revista de Formas Consensuais de Solução de Conflitos | e-ISSN: 2525-9679 | Encontro Virtual | v. 7 | n. 1 | p. 54 - 71 | Jan/Jul. 2021. 
Parte-se do entendimento de que a Justiça Restaurativa é um movimento histórico e que se disseminou pelo mundo, baseando-se por um processo de consenso, onde vítima, o infrator e outros membros da comunidade afetados pelo crime, participam coletiva e ativamente na construção de resoluções dos conflitos criminais.

\subsection{A evolução da Justiça Restaurativa}

Por ser um movimento historicamente, cultural e novo, o modelo de Justiça Restaurativa propriamente dito, teve seu início em meados da década de 70, mais precisamente ao final da década de setenta e cinco e início da década de oitenta, na Nova Zelândia e no Canadá. Segundo Adriana Orsini e Caio Lara (2013, p. 05), a Justiça Restaurativa foi baseada em estudos de povos com tradições antigas de primeira nação e, daí foi extraída diante de muitas observações. Renato Sócrates Gomes Pinto (2006, p. 3), assevera a respeito da sua existência que

A denominação justiça restaurativa é atribuída a Albert Eglash, que, em 1977, escreveu um artigo intitulado Beyond Restitution: Creative Restitution, publicado numa obra por Joe Hudson e Burt Gallaway, denominada "Restitution in Criminal Justice" (...). Eglash sustentou, no artigo, que havia três respostas ao crime - a retributiva, baseada na punição; a distributiva, focada na reeducação; e a restaurativa, cujo fundamento seria a reparação.

O primeiro país a positivar a prática da Justiça Restaurativa foi a Nova Zelândia. Conforme Aguiar (2009, p. 112), inspirado nos costumes dos aborígenes maoris, em 1989 editou-se nesse país o documento normativo denominado Children, Young Persons and Their Families Act, que reformulou o sistema de justiça da infância, contribuindo grandemente na prevenção e diminuição da reincidência de infratores. Tal norma instituiu o método de conferência de grupo familiar, assim como outras abordagens restaurativas incidentes sobre lides juvenis. Tamanho o sucesso da experiência desse país, as práticas restaurativas também foram aplicadas, de forma opcional, ao sistema de Justiça Criminal tradicional (ORSINI e LARA, 2013, p. 05-06).

Os programas de Justiça Restaurativa passaram a se disseminar pelo mundo a partir dos anos noventa, sendo adotados pela Austrália, Canadá, Estados Unidos, África do Sul, 
Argentina, Colômbia, dentre outros países. Muitos trabalhos doutrinários foram realizados nessa época em crítica à justiça penal retributiva. Conforme Orsini e Lara,

Em 1990, foi publicada a primeira edição daquela que é considerada a obra fundamental sobre Justiça Restaurativa. Changing Lenses: A New Focus for Crime and Justice (Trocando as Lentes: Um Novo Foco sobre Crime e Justiça - Scottsdale, PA: Herald Press), de Howard Zehr, foi um marco para a afirmação do novo modelo de justiça que se ora apresentava, que coloca as necessidades da vítima no ponto de partida do processo. Das ideias de Zehr (2008), extrai-se que a responsabilidade pelo ato lesivo e a obrigação de corrigi-lo devem ser assumidas pelo ofensor, que assim deixaria de ser um criminoso estigmatizado para se tornar protagonista de um processo restaurativo de participação comunitária, que vise a reparação dos danos, restauração de relacionamentos, a reorganização dos envolvidos e o fortalecimento da própria comunidade. $(2013$, p.6)

Assim, o conceito de Justiça Restaurativa tem uma nova definição da concepção de crime, ou seja, considera o delito, além de uma conduta contrária à norma criminal, um ato que atinge pessoas, causando danos e prejudicando relacionamentos.

\subsection{Impacto causado pela Resolução 2002/12 da ONU}

O impacto causado pela temática da Justiça Restaurativa foi tão grande no mundo, que as Organizações da Nações Unidas (ONU) acolheram o modelo reparatório por meio de uma resolução, na qual a ONU recomenda e incita os Estados Membros a adotar e desenvolver projetos de Justiça Restaurativa, estabelecendo ainda conceitos, princípios e diretrizes básicas para sua devida aplicação. Essa norma teve influência na adoção da metodologia restaurativa por vários países, incluído o Brasil.

É importante, ainda, destacar o preâmbulo da referida resolução, pelo simples fato de elucidar a importância da Justiça Restaurativa frente ao Direito Criminal,

\section{PREÂMBULO}

Considerando que tem havido um significativo aumento de iniciativas com justiça restaurativa em todo o mundo.

Reconhecendo que tais iniciativas geralmente se inspiram em formas tradicionais e indígenas de justiça que vêem, fundamentalmente, o crime como danoso às pessoas,

Enfatizando que a justiça restaurativa evolui como uma resposta ao crime, que respeita a dignidade e a igualdade das pessoas, constrói o entendimento 
e promove a harmonia social mediante a restauração das vítimas, ofensores e comunidades,

Focando o fato de que essa abordagem permite que as pessoas afetadas pelo crime possam compartilhar abertamente seus sentimentos e experiências, bem assim seus desejos sobre como atender suas necessidades,

Percebendo que essa abordagem propicia uma oportunidade para as vítimas obterem reparação, se sentirem mais seguras, e poderem superar o problema, permite os ofensores compreenderem as causas e consequências de seu comportamento e assumir responsabilidade de forma efetiva, bem assim possibilita à comunidade a compreensão das causas subjacentes do crime, para se promover o bem estar comunitário, e a prevenção da criminalidade.

Observando que a justiça restaurativa enseja uma variedade de medidas flexíveis e que se adaptam aos sistemas de justiça criminal e que complementam esses sistemas, tendo em vista os contextos jurídicos, sociais e culturais respectivos,

Reconhecendo que a utilização da justiça restaurativa não prejudica o direito público subjetivo dos Estados de processar presumíveis ofensores (ONU, 2002).

A influência da resolução 2002/12 não só causou impacto positivo no mundo, como também, afetou o constitucionalismo latino-americano. De acordo com Orsini e Lara, por exemplo, no ano de 2002 a Justiça Restaurativa alcançou status internacional na Colômbia, fazendo com que constasse até no Artigo 250 da Constituição do referido país e, também, com regulamentação na legislação ordinária, em seus Artigos 518 e seguintes, no Código de Processo Penal (2013, p. 9).

\subsection{Justiça Restaurativa x Justiça Retributiva}

A Justiça Restaurativa é baseada num processo de consenso, onde as duas partes, vulgo vítima e transgressor, ou também, quando se fizer necessário, a presença de outras pessoas ou indivíduos relacionados à comunidade afetada pelo crime, participam coletiva e ativamente na construção de soluções para a cura das feridas, dos traumas e perdas causadas pelo crime (PINTO, 2005, p. 20).

Para Pinto

Trata-se de um processo estritamente voluntário, relativamente informal, a ter lugar preferencialmente em espaços comunitários, sem o peso e o ritual solene da arquitetura do cenário judiciário, intervindo um ou mais mediadores ou facilitadores, e podendo ser utilizadas técnicas de mediação, conciliação e transação para se alcançar o resultado restaurativo, ou seja, um 
acordo objetivando suprir as necessidades individuais e coletivas das partes e se lograr a reintegração social da vítima e do infrator. (PINTO, 2005, p. 20)

No Brasil, é importante salientar que na Lei dos Juizados Especiais Cíveis e Criminais como no Estatuto da Criança e do Adolescente, foram adotadas medidas das práticas restaurativas, porém, não totalmente detalhadas e específicas, como por exemplo seus princípios, procedimentos, valores e resultados, como a ONU (Organização Das Nações Unidas) prevê na sua resolução 2002/12. De acordo com Pinto

O paradigma restaurativo vai além do procedimento judicial dos juizados especiais para "resgatar a convivência pacífica no ambiente afetado pelo crime, em especial naquelas situações em que o ofensor e a vítima tem uma convivência próxima", como pontua o juiz Asiel Henrique de Sousa, num estudo preliminar para a implantação de um Projeto Piloto em Brasília, no Núcleo Bandeirante. Em suas reflexões, ainda não publicadas, acrescenta ele que "em delitos envolvendo violência doméstica, relações de vizinhança, no ambiente escolar ou na ofensa à honra, por exemplo, mais importante do que uma punição é a adoção de medidas que impeçam a instauração de um estado de beligerância e a consequente agravação do conflito". No debate criminológico, o modelo restaurativo pode ser visto como uma síntese dialética, pelo potencial que tem para responder às demandas da sociedade por eficácia do sistema, sem descurar dos direitos e garantias constitucionais, da necessidade de ressocialização dos infratores, da reparação às vítimas e comunidade e ainda revestir-se de um necessário abolicionismo moderado. A justiça restaurativa é uma luz no fim do túnel da angústia de nosso tempo, tanto diante da ineficácia do sistema de justiça criminal como a ameaça de modelos de desconstrução dos direitos humanos, como a tolerância zero e representa, também, a renovação da esperança. (PINTO, 2005, p. 20-21)

Nesse caminho, Parker diz que

A justiça restaurativa é vista como um novo paradigma de conceitualização do crime e de resposta da justiça. O movimento centra-se mais no dano causado às vítimas e às comunidades do que nas leis não obedecidas, como ocorre na concepção tradicional de justiça criminal. Oriunda de raízes geográficas distintas e desenvolvida através de experiências práticas diferentes, a justiça restaurativa tem sido definida de vários modos diferentes. Algumas definições focalizam decisões específicas na condução dos processos; outras, resultados. A justiça restaurativa é uma resposta sistemática ao comportamento ilegal ou imoral, que enfatiza a cura das feridas das vítimas, dos infratores, e das comunidades afetadas pelo crime. (PARKER, 2005, p. 247-248) 
Por se tratar de um conceito relativamente "novo", a Justiça Restaurativa, ainda não possui um conceito definido de fato, o mais correto, frente a sua grande diversidade de orientações, práticas e afins, é considerá-la como um "modelo eclodido" (PALLAMOLLA, 2009, p. 54), pois o termo vem sendo modificado assim como suas práticas, desde suas experiências e, também, seus primeiros estudos.

Zehr, vê a Justiça Restaurativa como um modo de legitimação e resgate dos elementos restaurativos das nossas tradições, tradições que foram frequentemente desprezadas e reprimidas pelos colonizadores europeus (ZEHR, 2008, p. 256), e afirma que a Justiça Restaurativa moderna é uma adaptação de princípios, valores dos direitos humanos, expondo que
A Justiça Restaurativa:
1. Tem foco nos danos e consequentes necessidades (da vítima, mas também da comunidade e do ofensor).
2. Trata das obrigações resultantes desses danos (obrigações do ofensor, mas também da comunidade e da sociedade).
3. Utiliza processos inclusivos e cooperativos.
4. Envolve todos os que têm um interesse na situação (vítimas, ofensores, a comunidade, a sociedade).
5. Busca corrigir os males.

E continua dizendo que,

Às vezes descrevo a justiça restaurativa como uma roda. No centro dessa roda está o eixo, que é o esforço no sentido de "consertar" o mal feito, na medida do possível (item 5 acima). No entanto, a minha visão desse esforço se ampliou. Depois de ouvir as vítimas e também observar os participantes das conferências de grupos familiares na Nova Zelândia - e especialmente os participantes maoris, percebi que "corrigir" significa que devemos tratar dos danos e necessidades das vítimas, mas também as causas da ofensa. Assim, o plano que emerge das conferências de justiça para a juventude da Nova Zelândia deve ter duas partes fundamentais: u m plano para cuidar dos danos e necessidades da vítima, e u m plano para tratar daquilo que está acontecendo na vida do jovem ofensor e que contribuiu para levá-lo à ofensa. Isto representa u m esforço holístico para corrigir a situação. (ZEHR, 2008, p. 258)

Se tratando da Justiça Retributiva, esta possui a objetivação de punição, na qual o infrator é sancionado, fazendo com que se torne irrelevante a retribuição do mal do crime com o 
mal da pena, eliminando assim a conciliação ou transição, caracterizando-o exclusivamente como um agravo à sociedade.

Portanto,

\begin{abstract}
A justiça Retributiva sempre foi o horizonte do Direito Penal e do Processo Penal. Desprezava-se, quase por completo, a avaliação da vítima do delito. Obrigava-se quase sempre, a promoção da ação penal por órgãos estatais, buscando a punição do infrator. Levavam-se as últimas consequências a consideração de bens indisponíveis, a ponto de quase tudo significar ofensa a interesse coletivo. Eliminava-se, na órbita penal, a conciliação, a transação e, portanto, a mediação. Em suma, voltava-se a meta do direito Penal a uma formal punição do criminoso como se outros valores inexistissem. E a denominada Justiça Restaurativa, aos poucos, instala-se no sistema jurídico-penal brasileiro, buscando a mudança do enfoque supramencionado. Começa-se a relativizar os interesses, transformando-os de coletivos em individuais típicos, logo, disponíveis. A partir disso, ouvese mais a vítima. Transforma-se o embate entre agressor e agredido num processo de conciliação, possivelmente, até, de perdão recíproco. Não se tem punição do infrator como um único objetivo do Estado. A ação penal passa a ser, igualmente, flexibilizada, vale dizer, nem sempre obrigatoriamente proposta. Restaura-se o estado de paz entre pessoas que convivem, embora tenha havido agressão de uma contra a outra, sem necessidade do instrumento penal coercitivo e unilateralmente adotado pelo Poder Público. (NUCCI 2014, p. 314)
\end{abstract}

Também se faz necessário, dar enfoque no tratamento em como os envolvidos são tratados no modelo Retributivo, pois, o afastamento total da vítima do transgressor, que possuem um representante para falar no seu devido processo legal, sem ter quaisquer tipos de interferência para com o mesmo, como é observado em alguns casos de ações penais incondicionadas, onde o mesmo não pode nem se quer manifestar suas vontades.

Enfatizando o oposto, na Justiça Restaurativa a resolução do conflito tem maior participação das partes interessadas, a vítima, o acusado e a comunidade acometida pelo conflito. Com os ideais da Justiça Retributiva preservados, ainda assim, as partes podem expor seus sentimentos e necessidades de maneira consensual, para que se obtenha melhores resultados para as divergências.

Em contrapartida, a Justiça Retributiva tem uma finalidade mais punitiva que culmina na falta de solução para o problema dos conflitos, trivialmente por reprimir e não solver os casos em questão, há ainda a possibilidade de piorar as situações discutidas. Em oposição a Justiça Restaurativa que se baseia em uma perspectiva diferente ao sistema 
retributivo, evidenciando soluções às ineficácias do sistema de justiça criminal, alterando a ênfase do processo penal no desígnio da transgressão e penalidade, para o ato pernicioso, suas consequências e eventuais soluções.

Assim sendo, a Justiça Restaurativa não tem por objetivo abolir a Justiça Retributiva, mas melhorar as relações que se encontram em desacordo, que precisam de um consenso a fim de que se resolvam pendências, se reduz então, as divergências e o número de sentenças punitivas e maiores resultados nas deliberações de conflitos e o contentamento das partes envolvidas.

Portanto, como já observado, a Justiça Restaurativa é um procedimento de consenso, no qual a vítima, o infrator e, quando necessário, outros membros da comunidade afetados pelo crime, que como sujeitos centrais, participam coletiva e, ativamente, na construção de soluções dos danos e perdas causados pelo crime. Assim, a Justiça Restaurativa é um novo paradigma de resolução dos conflitos criminais.

Ademais, é necessário se compreender que o conceito de Justiça Restaurativa tem uma nova definição da concepção de crime, ou seja, considera o delito, além de uma conduta contrária à norma criminal, um ato que atinge pessoas, causando danos e prejudicando relacionamentos. E o sentido de restaurativa é mais amplo e envolve a restauração da paz social, a normalização das relações sociais e até a reabilitação psicoafetiva da vítima.

E esse instrumento de solução de conflitos vem evoluindo há aproximadamente dez anos, tanto que o Brasil tem vivenciado uma mudança nos paradigmas de tratamento de conflitos. Isso ocorre desde a Resolução $n^{\circ}$. 125/2010, do Conselho Nacional de Justiça, a concepção de acesso à justiça ultrapassou sua visão strictu sensu de acesso ao processo para ser compreendida como acesso ao tratamento adequado dos conflitos de interesses.

E, com a vigência da Lei nº 13.105/2015 (Novo Código de Processo Civil), a inserção dos métodos complementares de solução de conflitos, sendo a responsabilidade dos profissionais jurídicos o estímulo de sua implementação, ou seja, a regulamentação da mediação entre particulares como meio de solução de conflitos, fortaleceu o exercício da Justiça Restaurativa, in casu, nos conflitos criminais.

Foi, no entanto, com a Resolução $n^{\circ}$. 225/2016, do CNJ que a implementação da Justiça Restaurativa no Brasil obteve maior respaldo jurídico. Esse documento normativo propôs uma uniformização na conceituação dessas práticas, de forma a evitar discrepâncias de 
orientação e ação, no entanto, sem desconsiderar as especificidades das regiões brasileiras e das instituições envolvidas.

\section{A JUSTIÇA RESTAURATIVA COMO MEIO DE RESSOCIALIZAÇÃO DOS JOVENS ADULTOS}

Como visto, atualmente, o sistema penal brasileiro lida com o modelo retributivo para tentar responsabilizar e punir o infrator, sendo que este modelo está mais do que constatado que não vem surtindo efeitos positivos (ZEHR, 2008, p.168).

Além de não conseguir ressocializar o ofensor, o modelo retributivo também restringe a participação da vítima, não permitindo que esta demonstre suas necessidades e seus sentimentos em relação ao crime (ZEHR, 2008, p.168).

É nesse sentido que Howard Zehr em sua obra "Trocando as Lentes" tenta explicar a necessidade da busca de uma mudança de consciência do que se entende de crime, das necessidades do ofensor e da vítima, e, buscar por fim o sentimento de responsabilização no infrator, consequentemente a ressocialização do mesmo na comunidade.

O modelo retributivo, também, não é eficaz quando trata de coibir o jovem de cometer algum delito ou de fazer com que este não volte a praticar atos ilícitos (ZEHR, 2008, p.168).

Como os resultados pela busca da ressocialização não estão sendo eficazes foram feitas diversas modificações para modernizar este modelo. Implantaram monitoração eletrônica, uma supervisão intensiva na esperança de melhorar os resultados, porém o que deve ser levado em consideração é que estes meios só devem ser utilizados em última opção (ZEHR, 2008, p.168).

Então, como o próprio Howard explica, é necessário trocar as "lentes”, mudar a visão do que se entende sobre crime e justiça, assim,

Para achar a saída desse labirinto, teremos que procurar mais além de simples penas alternativas. Teremos que buscar formas alternativas de ver 0 problema e a solução. O professor Kay Harris, especialista em sentenciamento, nos faz lembrar que se trata de adotar valores diferentes, e não tecnologias de punição diferentes. (ZEHR, 2008, p.169). 
Quanto aos jovens infratores, necessário considerar as etapas da vida, pois, nelas se encontram várias mudanças ao ser humano sejam hormonais, físicas e psíquicas, visto que não apenas os afetam, como também refletem nas suas convivências em sociedade e familiares.

Salienta-se que todas essas mudanças roboram para que esses jovens tenham desvios de conduta, conduta esta reprovável ou não pela sociedade e, se for o caso, passível de punição. Também, que todo e qualquer delito praticado por estes deve ser avaliado por uma equipe multidisciplinar (psicólogo, assistente social, professores, promotores, juízes dentre outros que forem necessários) para avaliação in loco e a partir disso, tomar a decisão correta.

Importante destacar, ainda, que os jovens adultos devem ser tratados de forma humanizada, tentando incentivar neles o sentimento de responsabilidade, tanto para a vida pessoal e familiar quanto social. Educando os jovens infratores a não mais cometer delitos.

Assim, primeira mudança que deve ocorrer para que a aplicação da Justiça Restaurativa seja eficaz no Brasil é a transformação no modo de pensar da sociedade sobre crime, pois este tema deve ser visto como uma violação nas relações com as pessoas e, por isso cabe ao Estado consertar o que foi quebrado, sem violentas punições. (ZEHR, 2008, p. 170).

O delito para a Justiça Restaurativa e para Howard Zehr é considerado como um vínculo que irá existir entre a vítima e o ofensor, portanto se não for bem resolvido irá ocorrer um resultado negativo que em muitos casos são irreversíveis. (ZEHR, 2008, p. 171).

Por essa reflexão, entende-se que para a aplicação da Justiça Restaurativa a jovens que cometem crimes de menor potencial ofensivo, deve ser analisada, a situação delituosa, com uma nova visão.

Primeiramente, faz-se necessário enfatizar que após um delito, ambas as partes se encontram fragilizadas com a situação, sendo que o infrator começa a ser percebido na sociedade como condenável. (ZEHR, 2008, pp. 171-172).

A partir disso a Justiça Restaurativa quando aplicada fará de imediato um tratamento psicológico, tanto com a vítima quanto com o ofensor, preparando-os para um futuro encontro, onde tratarão de solucionar o conflito que os afligem.

Esse encontro inicial, que é essencial para o procedimento restaurativo, pois, é nele que os facilitadores irão preparar separadamente a vítima e o ofensor para um círculo restaurativo. Podendo participar deste primeiro momento qualquer pessoa da confiança do jovem para que este se sinta seguro, da mesma forma vale para a vítima, separadamente em 
ambiente seguro, onde serão utilizadas perguntas abertas e uma escuta ativa sobre a necessidade de cada um.

No procedimento restaurativo, propriamente dito, vítima e ofensor se encontram numa tentativa de solucionar o conflito e de gerar um sentimento de responsabilidade no jovem infrator. Nessa fase existirá um terceiro, denominado facilitador, que poderá em alguns casos ser até mesmo o juiz, onde este irá fazer o acolhimento dos envolvidos, uma breve apresentação dos que estão presentes no encontro, indicar o objetivo e a intenção do momento e depois explicar como funciona. Feita as considerações iniciais o facilitador conduzirá o procedimento restaurativo, de forma imparcial, fazendo perguntas que estimulem a fala para conscientização dos prejuízos, e, ao final deixar registrado em "termo" o que foi estabelecido e acordado.

Após um delito os procedimentos restaurativos podem ser iniciados antes, durante ou depois de uma ação penal. Uma vez que o jovem infrator irá reparar os danos causados àqueles que ele afetou. (JACCOUD, 2005, p. 172-174). O mais interessante é que se ocorra o procedimento restaurativo antes da propositura da ação, pois, não existirá mais a necessidade da propositura de uma ação penal.

Nessa linha de restauração e visando o melhor interesse social, vítima e autor, o Brasil positiva de forma clara mais um modelo de justiça restaurativa negocial, assim denomina de Acordo de Não Persecução Penal - art. 28, "a", do Código de Processo Penal o qual, em apertada síntese, traz a ideia de se obstar o início da persecução penal em juízo ante a prática de determinados delitos, condicional o "acordo", ao cumprimento e terminadas condições e em especial, trazendo um maior protagonismo à vítima do delito.

E tal instituto processual penal de viabilidade de uma maior discussão acusado (por meio da defesa técnica constituída), e órgão da acusação, toma maior relevância quando se trata do jovem adulto infrator que, uma vez obstado todo o estigma e o martírio processual penal até uma decisão processual penal final, depara com a real possibilidade de "barganha", resolução rápida, dinâmica e sem intercorrência no aspecto de seus antecedentes; num segundo momento, traz também a possibilidade real de reconhecimento do erro e da plena ressocialização de maneira menos invasiva.

Além da realidade do jovem infrator, não se pode deixar de enfatizar que tanto a sua vida como a da vítima foram lesadas e isto requer uma reparação à altura do dano causado, pois só assim evitará que o mesmo cometa delitos novamente, para tanto, o novo instituto 
como acima mencionado, traz de forma expressa a necessidade de reparação do dano como condição de homologação do instituto.

Assim sendo, ante a necessidade da implantação da Justiça Restaurativa no ordenamento jurídico para auxiliar os jovens infratores a se ressocializarem conscientemente e serem responsáveis sobre seus próprios atos vem de encontro com nova sistemática à positivação de referido instituto.

O que se busca para a efetiva implantação da Justiça Restaurativa em especial no aspecto processual penal como um novo paradigma se relaciona a nova estruturação de pensamento e efetividade na aplicação da lei e que se distancie do modelo pautado pelo caráter retributivo/ressocializador, trazendo um maior protagonismo no sentido enaltecer o papel da vítima no procedimento, bem como trazer uma orientação com natureza de exceção para utilização da pena.

Portanto, a linguagem jurídica em torno da construção da justiça tem como premissa a preservação do jovem adulto, encarada como uma fase peculiar do sujeito, dessa forma, merecendo uma abordagem não punitiva e, sim com o envolvimento de políticas sociais mais incisivas aptas a trazer a melhor solução.

\section{CONCLUSÃO}

O presente trabalho buscou avaliar a possibilidade de aplicação das práticas restaurativas, para tanto, desenvolveu-se uma pesquisa bibliográfica tendo como base doutrinadores que tratam do tema, bem como a legislação pertinente. De acordo com as concepções teóricas que nortearam este trabalho, existem dois modos de se fazer justiça criminal pelo Estado: justiça de forma retributiva ou restaurativa.

A prática de um ilícito penal, implica no Estado o poder-dever de punir aquele que violou o ordenamento jurídico, buscando restituir a paz social, retribuindo o mal causado em função do delito por meio da aplicação de medidas extremas, a pena. Assim, a pena privativa de liberdade acabou se tornando uma prática comum no atual sistema de justiça penal, sendo imposta como alternativa de resposta à infração penal e, também, como medida capaz de prevenir futuras condutas, além de ressocializar o infrator, situação que em função da estrutura carcerária brasileira, fica a quem dos índices aceitáveis. 
É nitidamente sabido que o ideal ressocializador não ocorre, indicando o fracasso do sistema de justiça penal vigente, já que o sujeito ativo do crime, ao ser submetido a uma pena que o prive de sua liberdade, é fruto de um processo de dessocialização ainda maior, o que lhe torna propenso ao cometimento de outros delitos.

A falência do atual sistema de justiça e suas penalidades indica a necessidade de um novo paradigma de justiça penal voltado a amenizar a fragilidade do atual e corrigir as suas falhas, é nesse ideário que surge a Justiça Restaurativa, mostrando-se como um novo modelo de solução de conflitos e cuja implantação não implica na supressão do modelo atual, já que a ideia é que a justiça punitiva e a restaurativa atuem de modo conjunto, uma complementando a outra.

A Justiça Restaurativa está baseada em procedimentos de consenso, onde a vítima e o infrator, e até mesmo outras pessoas ou membros da comunidade que foram afetados pelo crime, como elementos centrais, participam coletiva e ativamente na construção de soluções dos traumas e perdas causados pelo delito. A prática restaurativa parte da premissa de reparar o mal resultante da prática do ilícito, que não é visto, a priori, como um fato jurídico contrário à norma positiva imposta pelo Estado, mas sim como um fato ofensivo à pessoa da vítima e que quebra o pacto de cidadania reinante na comunidade.

Assim, o crime, para a Justiça Restaurativa, não é somente a conduta típica e antijurídica que atenta contra bens e interesses penalmente tutelados, mas, muito mais que isso, o interpreta como sendo uma violação nas relações entre infrator, a vítima e a comunidade, cabendo à Justiça Restaurativa identificar as necessidades e obrigações oriundas dessa relação e do trauma causado e que deve ser restaurado. Para tanto, buscando reparar o dano causado com a prática da infração, a Justiça Restaurativa, procura pelo diálogo entre os envolvidos no conflito, promover a responsabilização ativa, fazendo com que as responsabilidades pelo cometimento do delito sejam assumidas, as necessidades oriundas da ofensa sejam satisfatoriamente atendidas e a cura, ou seja, um resultado individual socialmente terapêutico, seja alcançado.

Cabe aqui mencionar que a Justiça Restaurativa tem sido entendida como um procedimento de consenso que envolve vítima, infrator e membros da comunidade atingida para discutir e propor soluções para os danos derivados da infração. Nesse aspecto ela se manifesta quando o crime já se efetivou. 
Por outro lado, as práticas restaurativas se mostram bem mais amplas, pois promovem, pelo uso de metodologias restaurativas que envolvem ações de diálogo, círculo, empoderamento, participação da comunidade como um todo; destacando e reforçando a vivência de valores civilizatórios, entre os quais se encontram a igualdade, o respeito, a liberdade.

Assim sendo, existe a necessidade da implantação da Justiça Restaurativa no ordenamento jurídico para auxiliar os jovens infratores a se ressocializarem conscientemente e serem responsáveis sobre seus próprios atos.

E, ainda, para se estabelecer a Justiça Restaurativa como um novo paradigma, deve se estruturar uma forma diferenciada de pensamento, que se distancie do modelo pautado pelo caráter retributivo, no sentido de enaltecer o papel da vítima no procedimento, bem como trazer uma orientação com natureza de exceção para utilização da pena que restringe a liberdade, de forma a exaltar formas de resolução de conflitos em que haja protagonismo das partes e a deliberação ocorra de forma negociada.

Portanto, a linguagem jurídica em torno da construção da justiça juvenil tem, como premissa, a preservação da infância e da adolescência, encarada como uma fase peculiar do sujeito, dessa forma, merecendo uma abordagem não punitiva e, sim com o envolvimento de políticas sociais, como por exemplo, educação, cultura e lazer.

\section{REFERÊNCIAS BIBLIOGRÁFICAS}

AGUIAR, Carla Zamith Boin. Mediação e justiça restaurativa: A humanização do sistema processual como forma de realização dos princípios constitucionais. São Paulo: Quartier Latin, 2009.

BRASIL. Código de Processo Civil - Lei $\mathbf{n}^{\mathbf{0} .13 .105 / 2015}$. Disponível em: <www.planalto.gov.br/ccivil_03/_ato2015-2018/2015/lei/113105.htm>. Acesso em: 14 fev. 2021.

BRASIL. Código de Processo Penal - DECRETO-LEI No 3.689, DE 3 DE OUTUBRO

DE 1941. Disponível em: < http://www.planalto.gov.br/ccivil_03/decreto-lei/del3689.htm>. Acesso em: 14 fev. 2021. 
CNJ. RESOLUÇÃO No 225, DE 31 DE MAIO DE 2016.: Disponível em: https://atos.cnj.jus.br/files/compilado160827202007275f1efbfbfOfaa.pdf. Acesso em 02 mar. 2021.

. CNJ. RESOLUÇÃO No 125, DE 29 DE NOVEMBRO DE 2010.: Disponível em: $<$ https://www.cnj.jus.br/wpcontent/uploads/2014/04/resolucao_125_29112010_23042014190818.pdf>. Acesso em 02 mar. 2021.

JACCOUD, Mylène. Princípios, Tendências e Procedimentos que Cercam a Justiça Restaurativa. In: SLAKMON, Catherine (Org.) et al.. Justiça Restaurativa. Ministério da Justiça e Programa das Nações para o Desenvolvimento - PNUD, 2005. p.163-186. Disponível em: <http://www.susepe.rs.gov.br/upload/1323798246_Coletania\%20JR.pdf>. Acesso em: 12 abr. 2021.

NUCCI, Guilherme. Manual de Direito Penal. - 10. ed. rev., atual. e ampl. - Rio de Janeiro: Forense, 2014.

ONU. Resolução 2002/12 - princípios básicos para utilização de programas de justiça restaurativa em matéria criminal. Tradução Renato Sócrates Gomes Pinto. [S.1.]: Justiça21, 2002. Disponível em: http://justica21.org.br/j21.php?id=366\&pg=0\#.V_ra0vkrLrc. Acesso em: 31 jan. 2021.

ORSINI, Adriana Goulart de Sena; LARA, Caio Augusto Souza. Dez anos de práticas restaurativas no Brasil: a afirmação da justiça restaurativa como política pública de resolução de conflitos e acesso à Justiça. Revista Responsabilidades (TJMG), Belo Horizonte, v. 2, n. 2, p. 305-324, set. 2012/fev. 2013. Disponível em: https://www.academia.edu/4369462/Dez_anos_de_pr\%C3\%A1ticas_restaurativas_no_Brasil. Acesso em 13 mar. 2021.

PALLAMOLLA, Raffaella Da Porciúncula. Justiça restaurativa: da teoria à prática. São Paulo: IBCCRIM, 2009.

PARKER. L. Lynette. Justiça Restaurativa: Um Veículo para a Reforma? In: SLAKMON, Catherine (Org.) et al.. Justiça Restaurativa. Ministério da Justiça e Programa das Nações para o Desenvolvimento - PNUD, 2005. p. 249-268. Disponível em: 
<http://www.susepe.rs.gov.br/upload/1323798246_Coletania\%20JR.pdf>. Acesso em: 12 abr. 2021.

SLAKMON, C., R. de Vitto; PINTO, E. R. Gomes (Org.). Justiça Restaurativa. Brasília: PNUD, 2005. Ministério da Justiça e Programa das Nações para o Desenvolvimento - PNUD, $2005 . \quad$ Disponível em: <http://www.susepe.rs.gov.br/upload/1323798246_Coletania\%20JR.pdf>. Acesso em: 12 abr. 2021.

ZEHR, Howard. Trocando as Lentes: um novo foco sobre o crime e a justiça. 1. ed. São Paulo: Palas Athena, 2008. 